\title{
Trabalho e cuidado no Direito: perspectivas de sindicatos e movimentos feministas
}

\author{
REGINA STELA CORREA VIEIRA I
}

\section{Introdução}

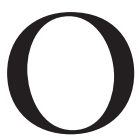
TRATAMENTO jurídico dado ao cuidado no Brasil e as políticas públicas voltadas à socialização das atividades de reprodução social ficam aquém das demandas sociais, ${ }^{1}$ reproduzindo e nutrindo a desigualdade de gênero no país. Seja tomado em sua acepção mais estrita - enquanto atividade de cuidar de crianças, idosos, pessoas com deficiência e doentes -, seja como um conceito amplo, que cobre várias dimensões da vida social - desde "práticas, atitudes e valores relacionados com o afeto, o amor e a compaixão nas relações intersubjetivas", até as ações do Estado e as políticas públicas voltadas aos segmentos da população tidos como dependentes (Hirata; Debert, 2016, p.7) -, o cuidado tem sido destacado por diversas vertentes teóricas como variável central para os estudos de gênero.

A teoria feminista (Fisher; Tronto, 1990; Molinier et al., 2009; Fraser, 2016) e a sociologia do trabalho, do gênero e das emoções (Hochschild, 2003; Hirata; Guimarães, 2012; Abreu et al., 2016) trazem grandes contribuições com pesquisas voltadas à divisão sexual do trabalho e às formas de exercício das atividades relacionadas ao cuidado (ou care) pelas mulheres, enquanto a economia feminista (Carrasco, 2011; Federici, 2012; Folbre, 2003), discute a invisibilidade do trabalho de cuidado e a necessidade do reconhecimento de seu papel central para a manutenção das condições de vida.

Tendo como enfoque o trabalho, essas diversas áreas do conhecimento têm-se debruçado para compreender e identificar as barreiras para as mulheres se estabelecerem como socialmente iguais, uma vez que no sistema capitalista o cuidado é uma atividade desvalorizada - e, por vezes, nem mesmo considerada "trabalho" -, cujo fardo recai quase que exclusivamente sobre as mulheres. Ademais, colocam em xeque paradigmas científicos universais, recorrendo à perspectiva de gênero para demonstrar que modelos supostamente assexuados partem, em verdade, de estereótipos masculinos (Hirata; Kergoat, 2008, p.44).

$\mathrm{Na}$ esfera jurídica, a igualdade perante a lei e seus desdobramentos legislativos e jurisprudenciais têm como paradigma a Constituição de 1988, mas ainda com resistência e sem efeitos práticos esperados por parte dos juristas. Em 
âmbito trabalhista, os artigos da CLT evidentemente sexistas foram revogados a partir de $1989^{2}$ e normas de não discriminação foram gradativamente promulgadas, incluindo a proibição de revistas íntimas e de pedido de exame de gravidez para contratação ou permanência no emprego (Lei n.9.799/1999).

Entretanto, não há apenas uma distância abissal entre prescrição normativa e sua efetividade em termos do combate à discriminação de gênero no trabalho, como essa mesma é reforçada por padrões sexistas nele arraigadas. Nesse sentido, reconhecendo o papel do direito na dominação social, o modo como o cuidado é positivado ou excluído das normas trabalhistas tem influência na reprodução da opressão de gênero - e de raça - no Brasil. Contraditoriamente, porém, o direito é também campo relevante para as lutas sociais (Melo, 2015, p.770), cujas reivindicações muitas vezes estão articuladas em torno da linguagem dos direitos.

Diante disso, o presente artigo propõe uma análise do trabalho e do cuidado no direito, mas considerando o modo como ambos são tratados por movimentos que estão no centro dos debates sobre cuidado no Brasil: organizações trabalhadoras do cuidado e movimentos feministas. Justifica-se essa escolha pela importância dos movimentos de mulheres no país, que desde o final dos anos 1970 reivindicam o reconhecimento e a socialização do trabalho doméstico, inclusive com papel de destaque em momentos cruciais da organização jurídica do país, como a Assembleia Nacional Constituinte (Teles, 1999).

Assim, tomo como ponto de partida a seguinte pergunta: como o direito do trabalho é articulado nas reivindicações de movimentos feministas e organizações de trabalhadoras que têm em suas pautas questões relativas ao trabalho de cuidado? Minha hipótese é de que o direito do trabalho, nos moldes tradicionais, não é um instrumento que responde às demandas desses grupos, representando muito mais um limitador que um impulsionador da igualdade almejada por elas.

Vale ressaltar que este artigo é fruto de um trabalho mais amplo, no qual desenvolvo uma crítica à noção de trabalho que alicerça o direito do trabalho brasileiro, colocando em teste o próprio escopo da disciplina (Vieira, 2018). Logo, a análise aqui proposta está circunscrita a tal contexto, tratando-se de uma das frentes da pesquisa de doutorado intitulada "O trabalho como cuidado: uma interpelação do direito do trabalho a partir da perspectiva de gênero", defendida em 2018 na Universidade de São Paulo. ${ }^{3}$ A proposta a ser desenvolvida aqui, porém, não irá se aprofundar na teoria do direito do trabalho, tampouco pormenorizar debates jurídicos sobre institutos trabalhistas. Pelo contrário, o esforço é no sentido refletir sobre possibilidades de o direito melhor responder às demandas sociais, dando voz às trabalhadoras do cuidado e às feministas organizadas.

Em termos metodológicos (Goldenberg, 2004), com respaldo na feminist standpoint theory (Harding, 2004), foram realizadas 10 entrevistas, entre 2016 e 2018, com integrantes de organizações sindicais de trabalhadoras domésticas ou cuidadoras e de movimentos de mulheres. ${ }^{4}$ Complementarmente, pesquisas 
bibliográfica e documental auxiliaram na análise das entrevistas, que em parte será apresentada com um breve panorama sobre o processo legislativo e a promulgação de leis sobre trabalho doméstico e de cuidado no Brasil.

\section{Percepções sobre o tratamento jurídico do cuidado no Brasil}

Com enfoque no trabalho de cuidado remunerado, importante elucidar que seu tratamento jurídico no Brasil tem relação direta com a peculiar realidade nacional da provisão de cuidado, por confluência de fatores históricos, territoriais e socioeconômicos. Destaco, primeiramente, que diferentemente da Europa e da América do Norte, a provisão de cuidado público no país nunca foi universal, de modo que a grande maioria das mulheres depende de redes de apoio ou paga outras mulheres para assumirem o trabalho de cuidado a elas designado socialmente. Além disso, as trabalhadoras do cuidado são identificadas, em sua maioria, como trabalhadoras domésticas em sentido amplo, responsáveis por tarefas que vão da faxina ao cuidado de crianças e idosos, o que demonstra "escasso reconhecimento institucional de que gozam essas profissionais" (Guimarães et al., 2012, p.87).

Para se ter dimensão da expressividade dessa atividade, no Brasil há 6,3 milhões de trabalhadores domésticos, dos quais 5,8 milhões são mulheres (IBGE, 2018a, p.26). A raça também é marcante nessa profissão, pois $65,9 \%$ das pessoas nela ocupadas são pretas ou pardas, nos termos do IBGE (2018a, p.27). Curioso destacar que uma categoria composta majoritariamente de mulheres negras é também a que possui menor rendimento médio do país, de $\mathrm{R} \$ 832,00$, abaixo inclusive do salário mínimo (IBGE, 2018a, p.23). Os baixos rendimentos têm relação com o fato de o trabalho doméstico ser a atividade com maiores índices de informalidade, chegando a 70,1\% do total (IBGE, 2018a, p.44).

O marco da segregação jurídica do trabalho doméstico no Brasil ${ }^{5}$ é a CLT, promulgada em 1943, que em seu artigo $7^{\circ}$ determinou que os direitos ali previstos não se aplicariam "aos empregados domésticos, assim considerados, de um modo geral, os que prestam serviços de natureza não-econômica à pessoa ou à família, no âmbito residencial destas" (Brasil, 1943). A comissão responsável pela organização da CLT justificou essa exclusão alegando que o trabalho doméstico seria diferente das demais formas de prestação de serviço, pois “a vida familiar apresenta aspectos de nenhuma similaridade com as atividades econômicas em geral" (Monteiro et. al., 1943, p.3).

Por conta dessa escolha, as trabalhadoras domésticas permaneceram três décadas em um constrangedor limbo jurídico (Delgado, 2017, p.380), que foi alterado pela edição da Lei n.5.859, de 1972. Na prática, essa lei formalizou um tratamento inferior à categoria em relação aos demais trabalhadores, negando garantias como salário mínimo, o descanso semanal remunerado e fundo de garantia por tempo de serviço. Essa realidade se manteve com poucas alterações ${ }^{6}$ até a Assembleia Nacional Constituinte, em 1987, na qual as demandas do movimento de trabalhadoras domésticas por ampliação de direitos ganharam corpo. 
O pleito inicialmente levado à Constituinte, tanto pelo movimento de mulheres (CNDM, 1987) quanto pelo movimento negro (Santos, 2015, p.126), era de equiparação de direitos, de modo que a CLT passasse a ser aplicada também às trabalhadoras domésticas. Com a mobilização intensa e cerca de 300 representantes da categoria ali presentes (Santos, 2010, p.4), elas conseguiram espaço em audiências públicas. Ainda assim, a tramitação da proposta foi árdua, sendo necessárias várias rodadas de negociação para se chegar a uma redação final: o trabalho doméstico não foi equiparado ao trabalho urbano e rural na Constituição de 1988 , mas foi criado o parágrafo único em seu artigo $7^{\circ}$, no qual foram estendidos alguns dos direitos trabalhistas à categoria. ${ }^{7}$ Assim, salário mínimo, $13^{\circ}$ salário, repouso semanal remunerado, férias remuneradas e licença-maternidade passaram a ser garantidos às trabalhadoras domésticas.

Apesar do significativo avanço, as trabalhadoras domésticas permaneceram sendo juridicamente tratadas como categoria apartada e com menos direitos. Por isso, a mobilização das trabalhadoras domésticas não cessou ao longo da década de 1990, tendo conquistado avanços como fundo de garantia por tempo de serviço facultativo (Lei n.10.208/2001), descanso remunerado nos feriados, estabilidade para gestante e vedação de descontos salariais por fornecimento de alimentação, vestuário, higiene ou moradia (Lei n.11.324/2006).

Em 2008, a criação de dois grupos de trabalho para discutir mudanças nas normas nacionais e internacionais sobre trabalho doméstico (Godinho, 2018), no governo Lula (2003-2010), foi crucial ${ }^{8}$ nos avanços jurídicos mais marcantes para a categoria na década posterior: a Convenção 189 da Organização Internacional do Trabalho, de 2011, ratificada no Brasil pelo Decreto Legislativo n.172/2017; e a Emenda Constitucional 72, de 2 de abril de 2013.

Os debates em torno desta última, conhecida como "PEC das Domésticas", tinham como interlocutores o governo, os sindicatos e a federação das trabalhadoras domésticas, bem como parlamentares, com destaque para Benedita da Silva (Godinho, 2018). A proposta de redação inicial da PEC era de revogação do parágrafo único do artigo $7^{\circ}$ da Constituição, de maneira a "estabelecer a igualdade de direitos trabalhistas entre os empregados domésticos e os demais trabalhadores urbanos e rurais", nos termos do projeto apresentado à Câmara dos Deputados.

No entanto, o texto final da EC $72 / 2013$, negociado com o Congresso, não revogou nenhum dispositivo constitucional, mas estendeu às trabalhadoras domésticas 16 novos direitos por meio de inserção de incisos nesse mesmo parágrafo único, alguns com efeito imediato e outros dependentes de regulamentação legal (Delgado, 2017, p.423). Na avaliação de Maria Betânia Ávila (2016, p.139), a regulamentação da jornada de trabalho para o trabalho doméstico, por exemplo, constituiu "uma nova ruptura com a herança escravista de um tempo de trabalho remunerado sem determinação de horário para começar nem para terminar". 
A fim de regulamentar a EC 72/2013, foi redigido, por Comissão Mista destinada a tal propósito, projeto de lei que viria a ser aprovado como Lei Complementar n.150, de 2015. Ela regulou amplamente o contrato de trabalho doméstico no direito brasileiro, revogando a Lei n.5.859/1972 e prevendo aplicação subsidiária da CLT às trabalhadoras domésticas, mas não foi bem aceita pela categoria, porque incluiu diversas concessões aos empregadores e, novamente, reduziu garantias trabalhistas. Exemplificam essa problemática previsões como o "banco de horas doméstico", o regime 12 por 36 para a categoria e o reconhecimento do vínculo empregatício apenas para trabalhadoras que prestam serviços "por mais de dois dias por semana", excluindo da lei as chamadas "diaristas".

A esse respeito, Creuza Oliveira (2016), da Federação Nacional das Trabalhadoras Domésticas (Fenatrad), disse que ela e as demais integrantes da organização não viam sentido no fato de terem conquistado um direito que, posteriormente, precisou ser regulamentado e limitado. Nas suas palavras:

“[...] pegaram uma comissão de regulamentação cheia de macho, não tinha uma mulher, e é uma comissão que não entende, e não quer entender de trabalho doméstico. [...] Essa Lei Complementar 150/2015 tem artigos que são inconstitucionais, como, por exemplo, o banco de horas que só pode acontecer se houver sindicato patronal e sindicato dos trabalhadores para negociar. Então continua o banco de horas para não pagar horas-extras. Tem também a empregada viajante, que a trabalhadora viaja com o patrão e só recebe $20 \%$ a mais do salário, sendo que ela está à disposição e não recebe horas-extras e nem adicional noturno. Tem a trabalhadora diarista, como criaram essa modalidade para poder continuar tendo trabalhadora doméstica em suas casas sem se responsabilizar em assinar a carteira de trabalho. Isso fez com que esse trabalho, que já era precarizado e terceirizado, continuasse dessa forma." (Oliveira, 2016)

Por isso, quando perguntada sobre suas percepções em relação ao tratamento jurídico do trabalho doméstico após a aprovação da Lei Complementar n.150/2015, Creuza afirmou que a Fenatrad continua lutando pela "equiparação de fato" (Oliveira, 2016). De forma similar, a presidenta do Sindicato dos Trabalhadores Domésticos do Município de São Paulo, Silvia Santos (2017), declarou que a reivindicação do sindicato é pela equiparação da categoria e pela efetivação dos direitos conquistados em 2013 (Santos, 2017). Para Silvia, “o importante mesmo que veio foi o FGTS, essa parte de seguro desemprego, que ajuda, mas ainda têm coisas necessárias para se equiparar com as outras profissões" (Santos, 2017).

Portanto, a principal crítica das trabalhadoras domésticas organizadas em relação à atual regulação de sua profissão deriva da percepção de que o trabalho doméstico ainda não é visto como um trabalho de igual valor - não merecendo iguais direitos - em comparação às demais atividades econômicas. Ainda assim, as garantias do contrato de trabalho são centrais em discursos como o de Silvia, justificado com o seguinte exemplo: "eu vejo minha mãe, ela trabalhou quarenta 
anos com a mesma família e voltou para casa, com uma mão na frente e outra atrás, andando, porque ela não tinha dinheiro nem para a passagem" (Santos, 2017).

\section{Cuidado como direito das mulheres}

No que tange o tratamento do cuidado nas pautas dos grupos entrevistados, ficou claro nas falas das interlocutoras que as organizações profissionais de empregadas domésticas, a federação de enfermeiras e associação de cuidadoras de idosos têm como prioritárias, em sua agenda política, reivindicações que envolvem o reconhecimento e garantias de direitos para as categorias, enquanto as organizações feministas demonstram preocupações que englobam, de modo mais claro, os debates sobre opressão de gênero e divisão sexual do trabalho (Vieira, 2018).

Nas entrevistas sobressaiu certa separação entre a luta por direitos trabalhistas e por direitos das mulheres. Foi observado que, na percepção da maioria delas, o direito do trabalho é entendido como assegurador do contrato de trabalho e das garantias a ele vinculadas, como previdência social e seguro desemprego. Assim, em especial no âmbito das organizações profissionais, por mais que a opressão de gênero, de raça, de orientação sexual etc. sejam uma preocupação, parecem apartadas dos debates trabalhistas (Vieira, 2018).

Creuza Oliveira (2016), por exemplo, considera que as demandas da Fenatrad abarcam diversas esferas, dentre as quais estão inseridas "também” reivindicações por escolas e creches, distinguindo as pautas relacionadas ao cuidado das pautas da organização que dizem respeito a direitos trabalhistas para a categoria. Em suas palavras:

"Eu sempre coloco que a luta das trabalhadoras domésticas não é só por reposição salarial, por data base, até porque a gente não tem data base. A nossa luta é mais ampla, pelo fato de nós sermos mulheres e sermos negra. [...] Então a gente luta também pela questão da educação, luta por creche, porque nós sabemos a importância de creches em período integral para que as mulheres possam trabalhar com segurança. A gente pode até dizer que a luta pelos direitos trabalhistas é nossa principal bandeira, mas existem diversas outras bandeiras." (Oliveira, 2016).

De forma ainda mais explícita, a presidenta da Associação dos Cuidadores de Idosos da Região Metropolitana de São Paulo, Lídia Nadir Giorge, faz uma divisão entre reivindicações trabalhistas e de mulheres. Para ela, “as cuidadoras sempre foram as mulheres", o que significa que "para as cuidadoras serem cuidadoras de outras pessoas, elas largam as famílias delas aos cuidados dos vizinhos e dos amigos". Partindo disso, porém, ela afirma que a luta da associação se restringe à regulação da profissão de cuidadora e cuidador ${ }^{9}$ e garantir a profissionalização, pois “a gente precisa ter uma profissão mais humana” (Giorge, 2017).

No caso da Federação Nacional dos Enfermeiros, Solange Aparecida Caetano (2017) deixou claro que as principais reivindicações da organização são a 
regulamentação da jornada de 30 horas semanais e o piso salarial nacional para a categoria, medidas que visam à valorização da enfermagem no país. Como complementares, ela elenca pautas relativas à "saúde da mulher", que incluem a inserção de "cláusulas nas convenções coletivas para dispensa da profissional pelo menos uma vez ou duas a cada seis meses para exames preventivos de câncer de útero e de mama", bem como a preocupação com o trabalho das gestantes em local insalubre e combate ao assédio moral (Caetano, 2017).

Durante a entrevista, Solange problematizou "o fato de as mulheres não terem creche para deixar os seus filhos, apesar de receberem auxílio creche, em muitos lugares o valor recebido não é o suficiente para colocar suas crianças em creches decentes", considerando o direito à guarda de filhas e filhos como "direto das mulheres". A esse respeito, ela afirmou haver uma resistência grande entre os sindicatos patronais que negociam com os profissionais da enfermagem "em relação a ampliar o que é direito das mulheres" (Caetano, 2017).

A coordenadora da Marcha das Margaridas, Alessandra Lunas (2017), explicou as especificidades do trabalho no campo, onde muitas vezes todos os integrantes da família trabalham mas só o homem recebe o salário, o que motiva reivindicações pela contratação das esposas e dos filhos desse trabalhador. Com relação à luta por creches, ela aparece apartada do debate de direitos trabalhistas das mulheres do campo. Segundo Alessandra, "a gente tem trazido a questão do cuidado, a luta pelas creches rurais", porque "autonomia dessas mulheres ainda é muito comprometida no campo, e isso tem a ver com criar estratégias para a gente discutir com essas mulheres os seus direitos, principalmente o de uma vida mais digna" (Lunas, 2017).

Nalu Faria, integrante da Sempreviva Organização Feminista (SOF), entende as creches como uma "reivindicação feminista", não devendo ser interpretadas somente como direito à educação da criança, já que a sua provisão reduz os encargos das mulheres de cuidarem de filhas e filhos, independente se elas estão ou não inseridas no mercado de trabalho. Para ela, a pauta do cuidado passa pela socialização desse tipo de trabalho, "que tem que ser assumido pelo Estado", mas também por "uma dimensão mais geral de como a sociedade tem que se organizar e criar outras alternativas para a dimensão do trabalho" (Faria, 2017).

$\mathrm{Na}$ fala de Maria Betânia Ávila, integrante do SOS Corpo - Instituto Feminista para a Democracia, também surgiu certa distinção entre o que são reivindicações trabalhistas e o que são reivindicações por direitos das mulheres. Em suas palavras:

"A gente defende os direitos trabalhistas não só ligados às categorias domésticas remuneradas, não. A gente defende mais amplamente não só a questão das trabalhadoras urbanas, mas também das trabalhadoras rurais, temas como direito à terra, direito ao crédito, a questão das jornadas de trabalho. A questão da creche é uma luta mais localizada com os movimen- 
tos de mulheres populares. A gente tem trabalhado muito com a questão das creches, na medida em que a luta pelas creches é muito importante nos níveis locais." (Ávila, 2017)

Por conseguinte, revela-se que para as interlocutoras, as pautas relacionadas ao cuidado e as pautas de direitos trabalhistas, ainda que dialoguem, não integram o mesmo campo de reivindicação. Ainda que cuidado seja trabalho, sua identificação pelos movimentos como na seara dos direitos das mulheres, seja por estratégia ou não, já lança luz sobre algumas limitações do direito do trabalho em face do cuidado, que serão aprofundadas no próximo item.

\section{O direito do trabalho como ferramenta incompleta}

As entrevistas indicam uma compreensão do direito como ferramenta para avançar na melhoria da vida das mulheres trabalhadoras, mas fica evidente que, para as interlocutoras, ele não é uma resposta em si, deixando muito a desejar (Vieira, 2018, p.183). Isso se reflete na seguinte fala de Creuza Oliveira (2016):

"A mulher que trabalha durante o dia e estuda a noite, muitas vezes tem que abrir mão do estudo, porque não tem creche nas universidades onde ela possa deixar seus filhos. [...] As domésticas, que saem para trabalhar e quase não tem creche onde deixar seus filhos. São várias as situações em que a legislação não protege as mulheres e o Estado não garante políticas publicas para a população, especialmente para as mulheres, de serviços públicos."

Na percepção de Eliete Silva (2017), do Sindicato das Trabalhadoras Domésticas de Campinas e Região, a resposta legal para o trabalho doméstico acabou trazendo piora nas condições de trabalho das mulheres. Segundo seu relato, o sindicato passou a receber um número crescente de trabalhadoras domésticas na informalidade e com cargas mais altas de trabalho depois da promulgação da Lei Complementar n.150/2015 (Silva, 2017).

Mesmo acreditando que os avanços na lei trabalhista "ajudaram muito" as trabalhadoras domésticas, Silvia Santos (2017), do sindicato de São Paulo, confirma que a situação está longe do ideal e que há obstáculos para que os direitos da categoria sejam efetivados. Em suas palavras, “os patrões ainda não entendem direito e não aceitam; os funcionários não sabem se impor para cobrar seus direitos; muitos não têm a informação. Falta muito para equiparar a outras áreas" (Santos, 2017).

Na perspectiva das enfermeiras, apresentada por Solange Caetano (2017), o direito do trabalho não contempla as especificidades do trabalho de cuidado com o paciente, por ser "muito focado nas normas, nas regras, que são utilizadas de forma geral". De forma semelhante, para Lídia Nadir Giorge (2017) "as leis não contemplam nem cuidadores nem contratantes”. Ela diz que é impossível aplicar as mesmas regras trabalhistas a um empregado de uma empresa e a uma cuidadora no ambiente doméstico, de modo que o direito precisaria ser sensível à realidade de quem cuida e de quem é cuidado (Giorge, 2017). 
Nalu Faria (2017), da SOF, afirma que "o campo do reconhecimento dos direitos, dentro de um determinado modelo, encontra um limite que é o limite daquele modelo. Para você ir mais além, tem que ter outro modelo". Dessa forma, ela entende que a ideia de "direitos" precisa ser redimensionada juntamente com as relações sociais e econômicas (Faria, 2017). Em uma perspectiva semelhante, Maria Betânia Ávila (2017) observa que

“[...] os direitos trabalhistas precisariam ser muito ampliados para responder as necessidades dos trabalhadores, mas, sobretudo, das trabalhadoras. Os que nós ainda temos não contemplam essa relação trabalho produtivo e reprodutivo, eles são todos instituídos tendo as mulheres como provedoras do trabalho reprodutivo."

A expressão "os que nós ainda temos" é marcante no trecho acima transcrito, pois expõe uma mudança relevante na forma de muitas dessas entidades se posicionarem publicamente em relação ao direito do trabalho - e aos direitos sociais como um todo. Frente à reforma trabalhista de 2017 e demais ataques a direitos sociais perpetrados desde então - como a reforma da previdência social (EC 103/2019) e a Lei da Liberdade Econômica (Lei n.13.874/2019) -, a defesa das garantias constitucionais e legais passou a ser a estratégia adotada por movimentos sindicais e por muitos movimentos de mulheres, na tentativa de combater e minimizar retrocessos.

\section{Novas estratégias desde a reforma trabalhista de 2017}

Os direitos sociais previstos pela Constituição de 1988 estão sob ataque sistemático desde 2016, quando o governo Michel Temer (2016-2018) assumiu o papel de propositor de uma série de reformas em diversas áreas da proteção social no Brasil. A reforma trabalhista, promulgada na Lei n.13.467/2017, foi o primeiro passo de uma sucessão de alterações jurídicas que viriam a ganhar escala ainda maior no governo de Jair Bolsonaro, que assumiu a presidência da República em 2019. O cenário de desmonte dos direitos sociais pela via jurídica, empreitado via reformas legislativas, decretos e até por decisões do STF, ${ }^{10}$ é agravado pelo fato de o país ter definitivamente cedido à pressão do capital pela financeirização desses mesmos direitos, relatada por economistas desde o começo dos anos 2000 (Lavinas, 2015).

Em relação ao direito do trabalho, entrada em vigor da reforma trabalhista de 2017 alterou, em profundidade, o modo como o Brasil trata essas normas, expondo de forma ainda mais evidente suas raízes sexistas e o fato de que socialmente as mulheres ainda são consideradas como força de trabalho secundária, de valor inferior à masculina (Vieira, 2018). Segundo Patricia Maeda (2018), alguns itens da reforma permitem vislumbrar esse tratamento diferenciado entre os sexos, por exemplo a expansão das formas de contratação autônoma e de precarização do vínculo contratual, que atinge em especial as mulheres que estão na informalidade e em outras atividades consideradas atípicas; ${ }^{11}$ e a criação de serviços com tempo de trabalho não tradicional, como o contrato intermitente, 
ou o trabalho em tempo parcial, ou o regime $12 \times 36$, que supostamente se enquadrariam melhor às responsabilidades familiares porque acabam como única alternativa das mulheres.

O fato de a reforma trabalhista ocorrer poucos anos depois da promulgação da EC 72/2013 e da Lei Complementar n.150/2015 é irônico, se não trágico, para as trabalhadoras domésticas. Se desde a década de 1940 a categoria buscava que as regras da CLT também fossem aplicadas a ela, o que foi conquistado em 2015, depois de 2017 essa aplicação subsidiária gerou alerta, por representar uma potencial redução de direitos recentemente conquistados. Nesse sentido, Luiza Pereira, atual presidenta da Fenatrad, afirma:

“A mudança na lei afetou toda a classe trabalhadora. A gente tem uma preocupação maior especialmente em dois pontos, a jornada intermitente e o negociado sobre o legislado [...]. Porque a jornada intermitente, mesmo com a carteira assinada, possibilita o empregador pagar só pelas horas trabalhadas e nós, trabalhadoras domésticas, que sempre fomos historicamente exploradas nessa questão da jornada de trabalho, sabemos que tem muito empregador que chama para trabalhar doze horas o dia. E digamos que no outro dia precisa trabalhar só três horas. E aí não fecha nem dois dias de trabalho somando as horas dos dois dias. No final do mês, o empregador só vai pagar aquele valorzinho das horas trabalhadas. [...] Então a gente discute muito isso, que foi muito prejudicial para as empregadas domésticas, principalmente porque existe uma correlação de forças em que a trabalhadora doméstica está mais desprotegida do que outras categorias." (Pereira, 2018)

Regina Teodoro (2017), do sindicato de Campinas, explicita a apreensão das trabalhadoras domésticas organizadas da seguinte maneira: “a gente apoiava aquilo de 2013 e não o que virou a Lei Complementar n.150/2015, que acabou com tudo; e agora vem o governo e acaba um pouco mais". Ela resume o desenrolar de um roteiro que é o seguinte: historicamente marginalizado em relação ao emprego "tradicional", o reconhecimento social e jurídico do trabalho doméstico e de cuidado foi conquistado em 2013, com uma refratária regulamentação em 2015, que veio, porém, seguido por uma reforma trabalhista e um período de desemprego crescente e altas taxas de informalidade, ${ }^{12}$ fazendo com que grande parte das conquistas pareçam perdidas.

Diante dessa conjuntura, Maria Betânia Ávila (2017) afirma que “[...] o nosso drama agora é que, mesmo com as suas restrições, estão querendo que estes direitos sejam destruídos”. Por isso, para ela, o momento é de mobilização para que que os direitos sociais permaneçam, "com uma luta de resistência, para depois eles avançarem”. "Não que a luta esteja separada, mas nesse momento uma questão crucial é garantir o que já conquistamos, na perspectiva de ampliação daqui para frente" (Ávila, 2017).

Alessandra Lunas (2017) também deixou claro estar preocupada com os efeitos que as reformas trabalhista e previdenciária podem causar na vida das trabalhadoras do campo: 
"Foram conquistas da Constituição de 1988, que fizeram muita diferença para a vida de muitas mulheres, mas que ainda não são unânimes e que a gente continuava lutando para que todas tivessem acesso. [...] Então, congelar os gastos de saúde e educação é dizer para as mulheres "vocês vão retroceder e voltar para dentro de casa". [...] Nesse momento, nossa resistência é principalmente contra os retrocessos, contra a visão conservadora do Congresso Nacional, que também tem trazido várias coisas para a pauta que leva ao retrocesso na vida das mulheres.” (Lunas, 2017)

Nas palavras de Luiza Pereira, da Fenatrad, esse é o momento de "continuar a luta”, não só pelas trabalhadoras domésticas, mas para todas as trabalhadoras e trabalhadores. Segundo ela:

"Sabemos que essa reforma trabalhista foi feita apenas para beneficiar o empregador. Apesar de que existe trabalhador que só de saber que aquele imposto sindical não vai mais ser descontado do salário dele, ele diz que foi ótimo. Só que ele não sabe que os direitos que ele tinha antes da reforma não foram fruto de uma luta individual dele, foi uma luta coletiva. Mesma coisa a trabalhadora doméstica. Os direitos que estão hoje conquistados para a categoria não contemplaram muitas das diretoras que estão nos sindicatos, porque são pessoas com mais de 60 anos, como é o meu caso. Nem por isso a gente deu um passo atrás [...]. Não, a luta continua, para garantir o que já conquistamos e possivelmente para ampliar.” (Pereira, 2018)

Logo, houve uma mudança de perspectiva entre as interlocutoras da pesquisa, uma vez que a necessidade de resistir contra o desmonte de direitos sociais tornou-se mote após a reforma trabalhista de 2017. Nesse sentido, as críticas ao direito e a afirmação da necessidade de incorporação de demandas feministas e de trabalhadoras do cuidado no ordenamento jurídico foram deixadas em segundo plano, dando lugar ao combate ao retrocesso. $\mathrm{O}$ próprio direito do trabalho ganhou mais destaque na fala das entrevistadas, uma vez que ele foi o primeiro alvo no projeto de desregulação da economia e sucateamento do Estado atualmente em curso no Brasil. ${ }^{13}$

\section{Conclusão}

A abordagem aqui proposta permitiu a elaboração de uma análise sobre o tratamento jurídico do cuidado no Brasil, com foco na perspectiva de integrantes de movimentos feministas e organizações de trabalhadoras domésticas e de cuidadoras. Neste breve retrato, se a negligência histórica do direito do trabalho em relação ao trabalho de cuidado revela o sexismo de suas bases, a luta das trabalhadoras domésticas permitiu a ampliação de seus direitos, especialmente pela Constituição de 1988 e Emenda Constitucional 72/2013.

Na busca por compreender o modo como direito é articulado nas reivindicações sociais, a hipótese de que o direito do trabalho, nos moldes tradicionais, não é um instrumento que responde às demandas desses grupos, representando mais um limitador que um impulsionador da igualdade, revelou-se parcialmente verdadeira. Por um lado, verificou-se uma segmentação na articulação de pautas 
referentes aos "direitos para as mulheres" e aos "direitos trabalhistas". Falar em "direito das mulheres" garante uma abrangência maior em relação ao escopo do direito do trabalho, ainda restrito ao contrato de trabalho. Por outro lado, o quadro de retrocessos assistido desde a reforma trabalhista de 2017 ameaça direitos sociais, inclusive os conquistados arduamente pelas trabalhadoras domésticas, tendo causado uma mudança no discurso dos movimentos estudados, que reduziram as críticas e passaram à defesa do direito do trabalho.

Conclui-se, portanto, que o direito do trabalho oferece respostas jurídicas insuficientes às demandas de movimentos feministas e organizações de trabalhadoras relativas ao cuidado, mas ainda representa socialmente um importante esteio no combate ao ímpeto desregulador e de enxugamento de garantias sociais em curso no Brasil. Vislumbra-se a necessidade de repensar as divisões disciplinares no direito, de modo a permitir um tratamento integrado das demandas por cuidado, respeitando as necessidades e garantindo uma vida digna para quem cuida e para quem é cuidado. Nesse sentido, trabalhar na ressignificação do conceito de trabalho produtivo tomado pelo direito, ou buscar o uso mais amplo da terminologia “direitos sociais" podem ser soluções que contribuam para romper barreiras jurídicas à igualdade de gênero.

\section{Notas}

1 Exemplo simples é o déficit de equipamentos de cuidado infantil no Brasil: 67,3\% (6,8 milhões) das crianças de 0 a 3 anos não frequentavam creches ou pré-escolas em 2017, um terço das quais tinham como barreira a falta de vaga ou a distância (IBGE, 2018 b, p.6).

2 Pontualmente é possível citar o artigo 446 da CLT, revogado pela Lei n.7.855 de 1989, que garantia a possibilidade de pai ou marido pleitear rescisão do contrato de trabalho "quando a sua continuação for suscetível de acarretar ameaça aos vínculos da família, perigo manifesto às condições peculiares da mulher ou prejuízo de ordem física ou moral para o menor" (Brasil, 1943). Para um panorama sobre essa evolução, ver Vieira (2019).

3 A referida pesquisa doutoral foi apoiada pela Fundação de Amparo à Pesquisa do Estado de São Paulo (Fapesp), processo 2016/18865-6.

4 Foram selecionados grupos com inserção social relevante e demandas relativas à temática do cuidado e de trabalho das mulheres, sendo eles: Federação Nacional das Trabalhadoras Domésticas (Fenatrad), Sindicato das/os Trabalhadoras/es Domésticas/os de Campinas e Região, Sindicato dos Trabalhadores Domésticos do Município de São Paulo, Federação Nacional dos Enfermeiros, Associação dos Cuidadores de Idosos da Região Metropolitana de São Paulo, Marcha das Margaridas, SOS Corpo - Instituto Feminista para Democracia e Sempreviva Organização Feminista (SOF).

5 Trabalho aqui com os marcos temporais tradicionalmente usados no direito do trabalho, mas faço a ressalva de que a compreensão das relações de trabalho no Brasil, em especial do trabalho doméstico, só é possível com a análise da escravização da população negra e do período de transição de 1888 a 1930 (cf. Telles, 2013). 
6 Houve a concessão de vale-transporte às trabalhadoras domésticas pela Lei n.7.418/1985, que foi expressamente aplicada por meio do Decreto n.95.247/1987.

7 “Art. $7^{\circ}$. [...] Parágrafo único. São assegurados à categoria dos trabalhadores domésticos os direitos previstos nos incisos IV, VI, VIII, XV, XVII, XVIII, XIX, XXI e XXIV, bem como a sua integração à previdência social".

8 O Executivo nacional criou um grupo de trabalho pra discutir a mudança de legislação do trabalho doméstico, junto com vários ministérios, que foi somada a uma segunda estratégia negociada entre governo federal e OIT, no sentido de fortalecer a participação das trabalhadoras domésticas brasileiras na Conferência que abordaria a temática (Vieira, 2018, p.155).

9 Depois de 12 anos em debate no Congresso Nacional, o PL 1385/2007, sobre a regulamentação da profissão de cuidador, foi vetado em 2019, no último estágio da tramitação, pelo presidente Jair Bolsonaro.

10 Destaco o julgamento da ADPF 324, publicado em 31 de agosto de 2018, em que o STF decidiu ser lícita a terceirização em todas as etapas do processo produtivo, em confronto com a jurisprudência construída pela Justiça do Trabalho (Súmula 331 do TST). Com essa decisão, deu-se aval a uma maior precarização das relações de trabalho, pois a terceirização no Brasil é utilizada na grande maioria das vezes para pagar menores salários, reduzir encargos trabalhistas e ocultar fraudes (cf. Silva, 2017).

11 Experiências profissionais que são realidade para a maioria das mulheres: "o total de ocupadas com 15 anos ou mais, 40\% estavam em atividades consideradas atípicas, como o trabalho doméstico, trabalhando por conta própria, em atividades não remuneradas ou trabalhando na produção para o próprio uso ou consumo; entre os homens, o percentual para o mesmo período era de $32 \%$, conforme dados da PNAD de 2015" (Teixeira, 2017, p.17).

12 O primeiro trimestre de 2019 computou a maior taxa de subutilização do Brasil desde 2012 , chegando a $25 \%$ da força de trabalho, ou 28,3 milhões de pessoas (IBGE, 2019). Ademais, desde de 2017 o número de trabalhadores informais superou o número de formais (Hirata, 2019).

13 Denominado por Gilberto Bercovici (2019) de "anarcocapitalismo”.

\section{Referências}

ABREU, A. R. P.; HIRATA, H.; LOMBARDI, M. R. Gênero e trabalho no Brasil e na França: perspectivas interseccionais. São Paulo: Boitempo, 2016.

ÁVILA, M. B. M. O tempo do trabalho doméstico remunerado: entre cidadania e servidão. In: ABREU, A. R. P.; HIRATA, H.; LOMBARDI, M. R. Gênero e trabalho no Brasil e na França: perspectivas interseccionais. São Paulo, Boitempo, 2016. p. 137-46.

SOS Corpo - Instituto Feminista para a Democracia. Entrevista concedida a

Regina S. C. Vieira e Fabiana S. Grecco [via Skype], 10 abr. 2017.

BERCOVICI, G. Anarcocapitalismo. Carta Capital, São Paulo, p.42-3, 28 ago. 2019.

BRASIL. Decreto-lei n.5.452, de $1^{\circ}$ de maio de 1943. Aprova a Consolidação das Leis do Trabalho. Brasília: Presidência da República, 1943.

CAETANO, S. A. Federação Nacional dos Enfermeiros. Entrevista concedida a Regina S. C. Vieira [mensagem eletrônica], 27 jan. 2017 
CARRASCO, C. La economía del cuidado: planteamiento actual y desafíos pendientes. Revista de Economía Critica, v.11, p.205-25, 2011.

CNDM. Carta das Mulheres à Assembleia Constituinte. Brasília: Conselho Nacional dos Direito da Mulher, Ministério da Justiça, 1987.

DELGADO, M. G. Curso de Direito do Trabalho. 16 ed. São Paulo, LTr, 2017.

FARIA, N. Sempreviva Organização Feminista. Entrevista concedida a Regina Stela Corrêa Vieira, São Paulo, 27 jan. 2017.

FEDERICI, S. Revolution at Point Zero: Housework, Reproduction, and Feminist Struggle. Oakland: PM Press, 2012. Não paginado (e-book).

FISHER, B.; TRONTO, J. Toward a Feminist Theory of Caring. In: ABEL, E. K.; NELSON, M. K. (Ed.) Circles of Care: Work and Identity in Women's Lives. Albany: SUNY Press, 1990. p.35-62.

FOLBRE, N. Who pays for the kids? Gender and the structures of constraints. 2 ed. New York: Routledge, 2003.

FRASER, N. Contradictions of capital and care. New Left Review [online], v.100, p.99117, jul./ago. 2016.

GIORGE, L. N. Associação dos Cuidadores de Idosos da Região Metropolitana de São Paulo. Entrevista concedida a Regina S. C. Vieira, São Paulo, 26 jan. 2017.

GODINHO, T. Secretaria de Políticas para as Mulheres da Presidência da República. Entrevista concedida a Regina S. C. Vieira, São Paulo, 26 abr. 2018.

GOLDENBERG, M. A arte de pesquisar: como fazer pesquisa qualitativa em Ciências Sociais. 8 ed. Rio de Janeiro: Record, 2004.

GUIMARÃES, N. A.; HIRATA, H.; SUGITA, K. Cuidado e cuidadoras: o trabalho do care no Brasil, França e Japão. In: GUIMARÃES, N. A.; HIRATA, H. (Org.) Cuidado e cuidadoras: as várias faces do trabalho do care. São Paulo: Atlas, 2012.

HARDING, S. Introduction: standpoint theory as a site of political, philosophic, and scientific debate. In: HARDING, S. (Ed.) The feminist standpoint theory reader: intellectual and political controversies. New York: Routledge, 2004.

HIRATA, H.; DEBERT, G. G. Apresentação. Cadernos Pagu [online], v.46, p.7-15, jan./abr. 2016.

HIRATA, H.; GUIMARÃES, N. A. (Org.) Cuidado e cuidadoras: as várias faces do trabalho do care. São Paulo: Atlas, 2012.

HIRATA, H.; KERGOAT, D. Paradigmas sociológicos e categoria de gênero. Que renovação aporta a epistemologia do trabalho? Novos Cadernos NAEA [online], v.11, n.1, p.39-50, jun. 2008 .

HIRATA, H. Trabalho: passado e presente. A divisão sexual do trabalho na crise. Slides da Conferência de Encerramento do XVI Encontro Nacional da ABET. Salvador, 2019.

HOCHSCHILD, A. R. Love and Gold. In: EHRENREICH, B.; HOCHSCHILD, A. R. (Ed.) Global Woman: nannies, maids, and sex workers in the New Economy. New York: Metropolitan Books, 2003. p.15-30.

IBGE. Sintese de indicadores sociais: uma análise das condições de vida da população brasileira. Rio de Janeiro: IBGE, 2018a. 
IBGE. Desemprego sobe para 12,7\% com 13,4 milhões de pessoas em busca de trabalho. Disponível em: <https://agenciadenoticias.ibge.gov.br/agencia-noticias/2012-agencia-de-noticias/noticias/24283-desemprego-sobe-para-12-7-com-13-4-milhoes-de-pessoas-em-busca-de-trabalho>. Acesso em: 20 jun. 2019.

Educação 2017 - PNAD Contínua. Rio de Janeiro: IBGE, 2018b. Disponível em: <https://biblioteca.ibge.gov.br/visualizacao/livros/liv101576_informativo.pdf>. Acesso em: 6 dez. 2019.

LAVINAS, L. A financeirização da política social: o caso brasileiro. Politika, Rio de Janeiro, n.2, p.35-51, jul. 2015.

LUNAS, A. C. Marcha das Margaridas. Entrevista concedida a Regina S. C. Vieira [Skype], 3 mar. 2017.

MAEDA, P. A contrarreforma na perspectiva da mulber trabalhadora: quando reformar significa precarizar. 8 mar. 2018. Disponível em: <https://www.jorgesoutomaior.com/ blog/a-contrarreforma-na-perspectiva-da-mulher-trabalhadora-quando-reformar-significa-precarizar>. Acesso em: 15 set. 2018.

MELO, T. Direitos e lutas sociais: a crítica jurídica marxista entre ambiguidade e resistência. In: KASHIURA JUNIOR, C. N.; AKAMINE JUNIOR, O.; MELO, T. Para a crítica do Direito: reflexões sobre teorias e práticas jurídicas. São Paulo: Outras Expressões, 2015. p.769-809.

MOLINIER, P.; LAUGIER, S.; PAPERMAN, P. Qu'est-ce que le care? Souci des autres, sensibilité, responsabilité. Paris: Payot \& Rivages, 2009.

MONTEIRO, L. A. R. et al. Relatório da Comissão. Diário Oficial dos Estados Unidos do Brasil, Suplemento ao n.3, 5 de janeiro de 1943. Disponível em: <https://juslaboris.tst.jus.br/>. Acesso em 11. mai. 2018.

OLIVEIRA, C. M. Federação Nacional das Trabalhadoras Domésticas. Entrevista concedida a Regina S. C. Vieira, Brasília, 10 nov. 2016.

PEREIRA, L. B. Federação Nacional das Trabalhadoras Domésticas. Entrevista concedida a Regina S. C. Vieira [via telefone], 13 abr. 2018.

SANTOS, J. K. C. Participação das trabalhadoras domésticas no cenário político brasileiro. In: Fazendo o Gênero 9 - Diásporas, Diversidades, Deslocamentos, 2010, Florianópolis. Anais do Fazendo Gênero. 9, Florianópolis, 2010, p. 1-9.

SANTOS, N. N. S. A voz e a palavra do movimento negro na Assembleia Nacional Constituinte (1987/1988): um estudo das demandas por direitos. São Paulo. 2015. Dissertação (Mestrado) - Escola de Direito de São Paulo, Fundação Getúlio Vargas. São Paulo, 2015.

SANTOS, S. M. S. Sindicato dos Trabalhadores Domésticos do Município de São Paulo. Entrevista concedida a Regina S. C. Vieira, São Paulo, 26 jan. 2017.

SILVA, E. F. Sindicato das Trabalhadoras Domésticas de Campinas e Região. Entrevista concedida a Regina S. C. Vieira [via telefone], 26 jan. 2017.

SILVA, H. B. M. Comentários à Reforma Trabalhista: análise da Lei 13.476/2017 artigo por artigo. São Paulo: Editora Revista dos Tribunais, 2017.

TEIXEIRA, M. O desmonte trabalhista e previdenciário: reinventando novas formas de desigualdades entre os sexos. Análise n. 26. São Paulo: FES, jul. 2017. 
TELES, M. A. A. Breve história do feminismo no Brasil. São Paulo: Brasiliense, 1999.

TELLES, L. F. S. Libertas entre sobrados: mulheres negras e trabalho doméstico em São Paulo (1880-1920). São Paulo: Alameda, 2013.

TEODORO, M. R. Sindicato das Trabalhadoras Domésticas de Campinas e Região. Entrevista concedida a Regina Stela Corrêa Vieira, Campinas, 9 nov. 2017.

VIEIRA, R. S. C. Cuidado como trabalbo: uma interpelação do Direito do Trabalbo a partir da perspectiva de gênero. São Paulo, 2018. 236p. Tese (Doutorado em Direito) Faculdade de Direito, Universidade de São Paulo. São Paulo, 2018.

. Direito e gênero na saúde e segurança das mulheres no trabalho. Belo Horizon-

te: Letramento, 2019.

RESUMO - O tratamento jurídico do cuidado no Brasil e as políticas públicas voltadas à socialização das atividades de reprodução social ficam aquém das demandas sociais. $\mathrm{O}$ Direito do Trabalho, que historicamente ignora ou negligencia o trabalho doméstico, remunerado ou não, teve avanços como a Emenda Constitucional 72/2013 e a ratificação da Convenção 189 da OIT, mas sofre atualmente com reforma trabalhista que ameaça os direitos conquistados arduamente pelas trabalhadoras domésticas. As vozes das integrantes de movimentos feministas e organizações de trabalhadoras domésticas revelam a segmentação entre luta por direitos para as mulheres e luta por direitos trabalhistas e a necessidade de repensar as divisões disciplinares no Direito. Ao mesmo tempo, evidenciam a preocupação com retrocessos jurídicos, que exige posturas efusivas em defesa dos direitos sociais.

PALAVRAS-CHAVE: Cuidado, Direito do trabalho, Movimentos feministas.

ABSTRACT - The legal treatment of care in Brazil and the public policies aimed to socialize activities related to social reproduction fall way behind the social demands. Labor Law, which historically ignored or neglected domestic work, paid or unpaid, was improved in the past few years, with, for instance, Constitutional Amendment 72/2013 and the ratification of ILO Convention 189. However, it currently endures a labor reform that threatens hard-earned rights for domestic workers. The voices of members of feminist movements and domestic workers' organizations reveal segmentation between their struggle for women's rights or labor rights and the need to rethink the disciplinary division of Law. At the same time, they also reveal political concern with potential legal setbacks and demand expressive protection of social rights.

KEYWORDS: Care, Labor law, Feminist movements.

Regina Stela Corrêa Vieira é doutora em Direito pela Universidade de São Paulo, professora do Programa de Pós-Graduação em Direito da Universidade do Oeste de Santa Catarina (Unoesc) e pesquisadora do Núcleo Direito e Democracia do Cebrap. @ - regina.vieira@unoesc.edu.br / https://orcid.org/0000-0002-4407-4867

Recebido em 12.12.2019 e aceito em 14.2.2020.

I Programa de Pós-Graduação em Direito, Universidade do Oeste de Santa Catarina, Chapecó, Santa Catarina, Brasil. 